\title{
Government Preference and the Optimal Choice of R\&D Subsidy Policy: Innovation Subsidy or Product Subsidy?
}

\author{
Yongcong Yang \\ Institute of Industrial Economics, Jinan University, Guangzhou 510632, China \\ Correspondence should be addressed to Yongcong Yang; yangyongcong3787@sina.com
}

Received 29 November 2013; Accepted 1 January 2014; Published 12 February 2014

Academic Editor: Pei-ai Zhang

Copyright (C) 2014 Yongcong Yang. This is an open access article distributed under the Creative Commons Attribution License, which permits unrestricted use, distribution, and reproduction in any medium, provided the original work is properly cited.

\begin{abstract}
Taking government preference into consideration, we consider a three-stage game model to compare the differences of innovation subsidy and product subsidy. The findings reveal that stronger preference to consumers' welfare leads to higher subsidy rates, which benefit not only consumers but also firms. To choose between the two subsidies, the optimal choice varies with the changing preference of policymakers. According to the results of numerical simulation, product subsidy is better than innovation subsidy in most cases, while the government's expenditure of the former one is larger than the latter one. Moreover, subsidizing firms symmetrically and asymmetrically has different effects on the consequences.
\end{abstract}

\section{Introduction}

Because of the fierce competition among countries, a growing number of $R \& D$ policies are formulated to strengthen the dynamics of innovation. The positive effectiveness of R\&D policies has been supported by many previous theoretical and empirical studies [1-4]. These studies believed that firms tended to increase their innovation activities and became more successful with R\&D subsidies [5-7]. On the other hand, some literature argued that subsidized firms tended to exhaust their advantages in competition $[8,9]$.

There are many options for policymakers to stimulate innovation, like $R \& D$ contest with prize, $R \& D$ investment subsidy, and product subsidy for innovation. Naturally, the effects of different policies vary, which has been confirmed by some literature. Fu et al. [10] found that both subsidy and prize were effective, while they were compliant with different market environments. Saracho and Usategui [11] concluded that fixed quantity subsidy was cheaper than subsidy rate to achieve a given welfare level.

This paper focuses on comparison of two major subsidy patterns, including innovation subsidy and product subsidy. As noted by D’Aspremont and Jacquemin [12], R\&D cooperation of firms could be executed in the investment stage and product stage. Likewise, R\&D subsidies often take place in input stage and output stage, corresponding to innovation subsidy and product subsidy, respectively. What are the differences of these two instruments? How to choose between them? To address the questions above, we establish a three-stage game to solve the equilibrium solutions and then conduct a numerical simulation for comparison.

Furthermore, this paper sets government preference as an important factor in the model. Maximization of social welfare is an appropriate goal for the government. While formulating subsidy policies to maximize social welfare, consumers and firms are the two major objects and components. Whether the government prefers to enhance consumers' surplus or firms' profits relates to different results. That is why we need to take the policymakers' preference into consideration.

The rest of this paper proceeds as follows. Section 2 presents the baseline model, considering a duopoly market with symmetric innovation subsidy and product subsidy. Section 3 extends the case of symmetric subsidies to asymmetric subsidies. Section 4 conducts a specific numerical simulation to make comparative analysis of innovation subsidy and product subsidy. Section 5 concludes this paper.

\section{Baseline Model and Analysis}

Suppose that there are two identical firms producing only one homogeneous product in some industry. That is, they are 
symmetric without any difference in production. Denote the two firms to be $i=1,2$ and the corresponding output to be $q_{i}$. Therefore, the total output of them is $Q=q_{1}+q_{2}$. Moreover, they compete in a Cournot fashion in the market.

Consider a three-stage game. In stage 1 , the government sets the optimal subsidy level to maximize the social welfare. In stage 2 , each firm decides its $\mathrm{R} \& \mathrm{D}$ input according to the subsidy policy. In stage 3 , firms in the same industry compete in quantities.

2.1. Consumers. The quasilinear utility function is given as follows:

$$
U(p, Q)=\alpha Q-\frac{1}{2} Q^{2}-p Q
$$

where $\alpha$ is a positive constant and $p$ stands for the price of the product. Because the utility function is strictly concave, the inverse demand function can be induced directly by the condition $\partial U(p, Q) / \partial Q=0$. With the above assumption $Q=$ $q_{1}+q_{2}$, the function can be written as

$$
p=\alpha-Q=\alpha-q_{1}-q_{2}
$$

2.2. Firms with Symmetric Innovation Subsidies. For each firm in the industry, its initial marginal cost is set to be $c_{0} \geq 0$. No fix cost exists at the beginning. With the R\&D investment $x_{i}$, firm $i$ 's marginal cost changes to be $c_{i}=c_{0}-r x_{i}$, where $r \in(0,1)$. Here, $r$ represents the conversion efficiency of innovation. Because marginal cost is always positive, we have $c_{0}>r x_{i}$. Definitely, $x_{i}$ and $r$ have a negative impact on $c_{i}$. The higher $x_{i}$ and $r$ are, the lower the marginal cost is. The profit function of firm $i$ is given by

$$
\pi_{i}=\left(\alpha-q_{i}-q_{j}\right) q_{i}-\left(c_{0}-r x_{i}\right) q_{i}-\frac{1}{2}(1-s) x_{i}^{2},
$$

where $s \in[0,1]$. Note that $s$ denotes the government subsidy and $(1 / 2)(1-s) x_{i}{ }^{2}$ is the cost of firm $i$ 's R\&D investment. We discuss the above model by backward induction.

In stage 3, firms compete in quantities to maximize their profits. By the first-order condition $\partial \pi_{i} / \partial q_{i}=0$, the equilibrium quantity can be derived as

$$
q_{i}=\frac{1}{3}\left(\alpha-c_{0}+2 r x_{i}-r x_{j}\right)
$$

Using (4), the function of net profit can be rewritten as

$$
\pi_{i}=\frac{1}{9}\left(\alpha-c_{0}+2 r x_{i}-r x_{j}\right)^{2}-\frac{1}{2}(1-s) x_{i}^{2} .
$$

In stage 2, firms decide their R\&D investments. Analogously, maximization of (5) leads to

$$
\frac{\partial \pi_{i}}{\partial x_{i}}=\frac{4 r}{9}\left(\alpha-c_{0}+2 r x_{i}-r x_{j}\right)-(1-s) x_{i}=0
$$

The solution of (6) is

$$
x_{i}=\frac{4 r\left(\alpha-c_{0}\right)}{9(1-s)-4 r^{2}} .
$$

On using (7) in (4) and (5) we note that

$$
\begin{gathered}
q_{i}=\frac{3\left(\alpha-c_{0}\right)(1-s)}{9(1-s)-4 r^{2}}, \\
\pi_{i}=\frac{\left(\alpha-c_{0}\right)^{2}(1-s)\left[9(1-s)-8 r^{2}\right]}{\left[9(1-s)-4 r^{2}\right]^{2}} .
\end{gathered}
$$

It is clear that $s$ has a positive effect on $x_{i}, q_{i}$, and $\pi_{i}$. Higher subsidy urges more investment on $\mathrm{R} \& \mathrm{D}$, thus bringing more production and higher net profit.

In stage 1 , government sets the innovation subsidy policy to maximize the social welfare, which equals the consumers' surplus plus firms' net profit minus government's expenditure on R\&D subsidy. Note that SW denotes social welfare and CS denotes consumers' surplus in the following equation:

$$
\begin{aligned}
\mathrm{SW} & =b \mathrm{CS}+\pi_{1}+\pi_{2}-\frac{1}{2} s x_{1}^{2}-\frac{1}{2} s x_{2}^{2} \\
& =b\left(\int_{0}^{q_{1}+q_{2}} p(Q) d(Q)-p Q\right)+\pi_{1}+\pi_{2}-\frac{1}{2} s\left(x_{1}^{2}+x_{2}^{2}\right),
\end{aligned}
$$

where $b \in(0,2)$ is a weight variable and represents the government preference. The government pays more attention to enhance consumers' welfare as $b \rightarrow 2$. If $b=1$, there exists no special preference between consumers and enterprises for the government. With $0<b<1$, the government attaches more importance to firms. Commonly, many developing countries focus on the development of enterprises and set GDP as the major target. To achieve the expected growth, these countries would rather sacrifice consumers' interest, implying that $b \in(0,1)$. Conversely, developed countries prefer to stand by consumers rather than firms. That is, we can obtain $b \in(1,2)$ in these countries. On using (7) and (8) in (9), the social welfare is given by

$$
\mathrm{SW}=\frac{2\left(\alpha-c_{0}\right)^{2}\left[9(1-s)^{2}(b+1)-8 r^{2}\right]}{\left[9(1-s)-4 r^{2}\right]^{2}} .
$$

Maximization of (10) with respect to $s$ leads to $s^{*}=1-$ $2 /(b+1)$. The second-order condition is shown as follows:

$$
\begin{aligned}
& \frac{\partial^{2} \mathrm{SW}}{\partial s^{2}} \\
& \quad=-\frac{288 r^{2}\left(\alpha-c_{0}\right)^{2}\left[\left(9 s-2 r^{2}\right)(b+1)+9(2-b)\right]}{\left[9(s-1)+4 r^{2}\right]^{4}}<0 .
\end{aligned}
$$

Proposition 1. The optimal innovation subsidy is determined by government preference only. As $b \leq 1$, the optimal subsidy is zero. Stronger preference to consumers' welfare leads to a higher innovation subsidy.

From the function of $s^{*}$, it is obvious that government preference $b$ is the sole influencing factor. Other variables, 
like initial marginal cost $c_{0}$ and innovation efficiency $r$, have no effect on $s^{*}$. If the government determines to cultivate firms' abilities of independent innovation and development, the best strategy is to set innovation subsidy rate at zero. It indicates that providing subsidy may undermine firms' abilities of innovation for $b \leq 1$. Otherwise, the government should provide innovation subsidies to firms, since it is beneficial to consumers.

Substitute $s^{*}=1-2 /(b+1)$ into (7), (8), and (10). The optimal $x_{i}, q_{i}, \pi_{i}$, and SW are outlined as

$$
\begin{gathered}
x_{i}^{*}=\frac{2 r\left(\alpha-c_{0}\right)(b+1)}{9-2 r^{2}(b+1)}, \\
q_{i}^{*}=\frac{3\left(\alpha-c_{0}\right)}{9-2 r^{2}(b+1)}, \\
\pi_{i}^{*}=\frac{\left(\alpha-c_{0}\right)^{2}\left[9-4 r^{2}(b+1)\right]}{\left[\left(9-2 r^{2}(b+1)\right]^{2}\right.}, \\
\mathrm{SW}^{*}=\frac{2\left(\alpha-c_{0}\right)^{2}(b+1)}{9-2 r^{2}(b+1)} .
\end{gathered}
$$

Proposition 2. Both $r$ and $b$ have positive effects on $x_{i}^{*}, q_{i}^{*}$, $\pi_{i}^{*}$, and $S W^{*}$, while the effect of $c_{0}$ on them is negative.

From (12), it is obvious that higher innovation efficiency brings more innovation investment, larger production, and higher net profit for firms, thus enhancing social welfare as well. Similarly, stronger government preference to consumers' surplus leads to the same results. That is, with stronger preference to consumers' welfare, the government should provide more innovation subsidies to encourage firms to reduce their production cost. Notice that consumers are not the only beneficiary group to enjoy benefits from the reduction of production cost. Firms are also beneficiaries since decreasing cost helps them enlarge the market scale. On the other hand, high initial marginal cost limits the expansion of production and exerts adverse effects on social welfare.

2.3. Firms with Symmetric Product Subsidies. Here we consider another case of firms with symmetric product subsidies. To distinguish from the former case, we set subsidy as $s^{\bullet}, \mathrm{R} \& \mathrm{D}$ input as $x_{i}^{\bullet}$, quantity as $q_{i}^{\cdot}$, net profit as $\pi_{i}^{\cdot}$, and social welfare as $\mathrm{SW}^{\bullet}$. The assumptions keep the same. For the $i$ th firm with product subsidy, its net profit is

$$
\pi_{i}^{\bullet}=\left(\alpha-\dot{q_{i}}-\dot{q_{j}}\right) \dot{q_{i}}-\left(c_{0}-r \dot{x}_{i}^{\bullet}-\dot{s}\right) \dot{q_{i}}-\frac{1}{2} x_{i}^{\cdot 2}
$$

For the government, the social welfare is outlined as

$$
\begin{aligned}
\mathrm{SW}^{\bullet} & =b \mathrm{CS}+\pi_{1}^{\bullet}+\pi_{2}^{\bullet}-s \dot{q}_{1}^{\bullet}-s \dot{q}_{2} \\
& =b\left(\int_{0}^{\dot{q_{1}}+\dot{q}_{2}} p(Q) d(Q)-p Q\right)+\pi_{1}^{\bullet}+\pi_{2}^{\bullet}-s\left(\dot{q_{1}}+\dot{q_{2}}\right) .
\end{aligned}
$$

In a three-stage game, the government and corporate decision-making process is the same as the former one. We derive the optimal solutions by backward induction, which are given by

$$
\begin{gathered}
s^{* *}=\frac{\left(\alpha-c_{0}\right)\left[9(2 b-1)-4 r^{2}\right]}{2\left(18-9 b-4 r^{2}\right)}, \\
x^{* *}=\frac{6 r\left(\alpha-c_{0}\right)}{18-9 b-4 r^{2}}, \\
q^{* *}=\frac{9\left(\alpha-c_{0}\right)}{2\left(18-9 b-4 r^{2}\right)}, \\
\pi^{*}=\frac{9\left(\alpha-c_{0}\right)^{2}\left(9-8 r^{2}\right)}{4\left(18-9 b-4 r^{2}\right)^{2}}, \\
\mathrm{SW}^{*}=\frac{9\left(\alpha-c_{0}\right)^{2}}{2\left(18-9 b-4 r^{2}\right)} .
\end{gathered}
$$

Here we omit the specific operation process since it is the same as Section 2.2. Note that $s^{* *}$ is derived from the first-order condition $\partial \mathrm{SW}^{*} / \partial s^{*}=0$. To guarantee $s^{* *}$ is the optimum, we add an additional condition $b<2-4 / 9 r^{2}$ here to ensure the second-order condition $\partial^{2} \mathrm{SW}^{\bullet} / \partial s^{\bullet 2}<0$. Because $0<r<1$, the additional condition is easy to be satisfied. The other variables shown in (16) are derived from (15).

Proposition 3. Both government's preference $b$ and firms' innovation ability $r$ have positive effects on equilibrium product subsidy $s^{* *}$, R\&D input $x_{i}^{* *}$, quantity $q_{i}^{\cdot *}$, net profit $\pi_{i}^{\bullet *}$, and social welfare $S W^{*}$, while the impact of initial marginal cost $c_{0}$ is negative.

As shown in (15) and (16), the greater $r$ and $b$ are, the higher $s^{* *}, x_{i}^{* *}, q_{i}^{*}, \pi_{i}^{* *}$, and $\mathrm{SW}^{*}$ are. If the government does not show any preference between consumers and firms, that is, $b=1$, the optimal product subsidy adapts to be $s^{* *}=\left(\alpha-c_{0}\right) / 2$, which is the only exception that $r$ has no impact on it. Similar to Proposition 1, stronger preference for consumers' welfare conducts to a higher product subsidy, thus stimulating the expansion of firms' production and leading to higher net profits. Therefore, not only consumers but also firms benefit from product subsidy. In addition, the increase of initial marginal cost $c_{0}$ leads to reduction of social welfare $\mathrm{SW}^{*}$ and other variables as well.

\section{Extension of the Baseline Model}

This section presents an extension of the baseline model, relaxing the assumption of symmetric subsidy in Section 2. As is known, symmetric subsidy seldom happens because of limited budget of the government. More commonly, only part of firms can get R\&D subsidies. That is why we need to relax the assumption to see what would happen. In this section, we suppose without any loss of generality that only firm 1 receives the subsidy. 
3.1. Firms with Asymmetric Innovation Subsidies. With asymmetric innovation subsidies, the net profit functions of firm 1 and firm 2 are given as follows:

$$
\begin{gathered}
\pi_{1}^{\prime}=\left(\alpha-q_{1}^{\prime}-q_{2}^{\prime}\right) q_{1}^{\prime}-\left(c_{0}-r x_{1}^{\prime}\right) q_{1}^{\prime}-\frac{1}{2}\left(1-s^{\prime}\right) x_{1}^{\prime 2}, \\
\pi_{2}^{\prime}=\left(\alpha-q_{1}^{\prime}-q_{2}^{\prime}\right) q_{2}^{\prime}-\left(c_{0}-r x_{2}^{\prime}\right) q_{2}^{\prime}-\frac{1}{2} x_{2}^{\prime 2} .
\end{gathered}
$$
as

Accordingly, the social welfare function can be outlined

$$
\begin{aligned}
\mathrm{SW}^{\prime} & =b\left(\int_{0}^{q_{1}^{\prime}+q_{2}^{\prime}} p(Q) d(Q)-p Q\right)+\pi_{1}^{\prime}+\pi_{2}^{\prime}-\frac{1}{2} s^{\prime} x_{1}^{\prime 2} \\
& =\frac{b}{2}\left(q_{1}^{\prime}+q_{2}^{\prime}\right)^{2}+\pi_{1}^{\prime}+\pi_{2}^{\prime}-\frac{1}{2} s^{\prime} x_{1}^{\prime 2} .
\end{aligned}
$$

Satisfying the first-order condition $\partial S W^{\prime} / \partial s^{\prime}=0$ and the second-order condition $\partial^{2} \mathrm{SW}^{\prime} / \partial s^{\prime 2}<0$, the optimal solution of $(18)$ is

$$
s^{\prime *}=\frac{(b-1)\left(16 r^{4}-24 r^{2}+9\right)}{8 r^{4}(b+2)-2 r^{2}(9 b+14)+9(b+1)} .
$$

Substitute $s^{\prime *}$ into the two firms' R\&D investment functions; the equilibrium R\&D investments of firm 1 and firm 2 are given specifically by

$$
\begin{aligned}
& x_{1}^{\prime *}=\frac{2\left(\alpha-c_{0}\right)\left[8 r^{4}(b+2)-2 r^{2}(9 r+14)+9(b+1)\right]}{81-16 r^{6}(b+2)+8 r^{4}(3 b+22)-9 r^{2}(b+26)}, \\
& x_{2}^{\prime *}=\frac{4 r\left(\alpha-c_{0}\right)\left[4 r^{4}(b+2)-r^{2}(3 b+20)+9\right]}{81-16 r^{6}(b+2)+8 r^{4}(3 b+22)-9 r^{2}(b+26)} .
\end{aligned}
$$

Likewise, the equilibrium quantities of the two firms are outlined as

$$
\begin{aligned}
& q_{1}^{\prime *}=\frac{3\left(\alpha-c_{0}\right)\left[4 r^{4}(4-b)+r^{2}(3 b-26)+9\right]}{81-16 r^{6}(b+2)+8 r^{4}(3 b+22)-9 r^{2}(b+26)}, \\
& q_{2}^{*}=\frac{3\left(\alpha-c_{0}\right)\left[4 r^{4}(b+2)-r^{2}(3 b+20)+9\right]}{81-16 r^{6}(b+2)+8 r^{4}(3 b+22)-9 r^{2}(b+26)} .
\end{aligned}
$$

Notice that $q_{1}^{\prime *}=q_{2}^{\prime *}$ as $b=1$. With the optimal decisions of $\mathrm{R} \& \mathrm{D}$ investment and production, the net profit functions of firm 1 and firm 2 can be yielded as follows:

$$
\begin{aligned}
\pi_{1}^{\prime *}= & \left(\alpha-c_{0}\right)^{2}\left[4 r^{4}(4-b)+r^{2}(3 b-26)+9\right] \\
& \times\left[81-32 r^{6}(b+2)+4 r^{4}(9 b+64)-9 r^{2}(b+30)\right] \\
& \times\left(\left[81-16 r^{6}(b+2)+8 r^{4}(3 b+22)-9 r^{2}(b+26)\right]^{2}\right)^{-1}, \\
\pi_{2}^{\prime *}= & \frac{\left(\alpha-c_{0}\right)^{2}\left(9-8 r^{2}\right)\left[4 r^{4}(b+2)-r^{2}(3 b+20)+9\right]^{2}}{\left[81-16 r^{6}(b+2)+8 r^{4}(3 b+22)-9 r^{2}(b+26)\right]^{2}} .
\end{aligned}
$$

For asymmetric innovation subsidies, the following results emerge from the solutions.

Proposition 4. With asymmetric innovation subsidies, the innovation investment of firm 1 is larger than firm 2, but it is not necessary that firm 1 would produce more than firm 2 .

Because of $x_{1}^{\prime *}-x_{2}^{\prime *}>0$, innovation subsidies stimulate firm 1 to invest more for innovation, while firm 2 lacks such an incentive. However, this does not mean that the production of firm 1 is larger than firm 2. The production scale of them depends on parameters $b$ and $r$. For $b=1$ or $r=\sqrt{3} / 2$, the two firms are symmetric and their production quantities are identical. As $b>1$ with $r \in(0, \sqrt{3} / 2)$, or $b<1$ with $r \in(\sqrt{3} / 2,1)$, firm 1 produces more than firm 2. Otherwise, firm 2 occupies the dominant position in production instead of firm 1 . Thus, even though the R\&D investments of subsidized firms change to larger scales, it does not help to get any additional market share or establish occupational position for those subsidized firms.

3.2. Firms with Asymmetric Product Subsidies. As assumed, firm 1 is the only one that gets product subsidy. Therefore, the net profit functions of firm 1 and firm 2 are

$$
\begin{gathered}
\pi_{1}^{o}=\left(\alpha-q_{1}^{o}-q_{2}^{o}\right) q_{1}^{o}-\left(c_{0}-r x_{1}^{o}-s^{o}\right) q_{1}^{o}-\frac{1}{2} x_{1}^{o 2}, \\
\pi_{2}^{o}=\left(\alpha-q_{1}^{o}-q_{2}^{o}\right) q_{2}^{o}-\left(c_{0}-r x_{2}^{o}\right) q_{2}^{o}-\frac{1}{2} x_{2}^{o 2} .
\end{gathered}
$$

Similarly, the function of social welfare is shown as follows:

$$
\begin{aligned}
\mathrm{SW}^{o} & =b\left(\int_{0}^{q_{1}^{o}+q_{2}^{o}} p(Q) d(Q)-p Q\right)+\pi_{1}^{o}+\pi_{2}^{o}-s q_{1}^{o} \\
& =\frac{b}{2}\left(q_{1}^{o}+q_{2}^{o}\right)^{2}+\pi_{1}^{o}+\pi_{2}^{o}-s q_{1}^{o} .
\end{aligned}
$$

Using backward induction method to solve this threestage game, the optimal solution of product subsidy for firm 1 is

$$
s^{o *}=\frac{\left(\alpha-c_{0}\right)\left(4 r^{2}-3\right)^{2}\left(4 r^{2}-18 b+9\right)}{128 r^{6}+48 r^{4}(3 b-14)-72 r^{2}(3 b-11)+81(b-2)} .
$$

Based on $s^{o *}$, we can yield other functions as listed from (26):

$$
\begin{aligned}
& x_{1}^{o *}=\frac{12 r\left(\alpha-c_{0}\right)\left[4 r^{2}(3 b+5)-16 r^{4}-9 b\right]}{128 r^{6}+48 r^{4}(3 b-14)-72 r^{2}(3 b-11)+81(b-2)}, \\
& x_{2}^{o *}=\frac{4 r\left(\alpha-c_{0}\right)\left[12 r^{2}(7-3 b)-32 r^{4}+27(b-1)\right]}{128 r^{6}+48 r^{4}(3 b-14)-72 r^{2}(3 b-11)+81(b-2)},
\end{aligned}
$$




$$
\begin{aligned}
& q_{1}^{o *}=\frac{9\left(\alpha-c_{0}\right)\left[4 r^{2}(3 b+5)-16 r^{4}-9 b\right]}{128 r^{6}+48 r^{4}(3 b-14)-72 r^{2}(3 b-11)+81(b-2)}, \\
& q_{2}^{o *}=\frac{3\left(\alpha-c_{0}\right)\left[12 r^{2}(7-3 b)-32 r^{4}+27(b-1)\right]}{128 r^{6}+48 r^{4}(3 b-14)-72 r^{2}(3 b-11)+81(b-2)}, \\
& \pi_{1}^{o *} \\
& =\frac{9\left(\alpha-c_{0}\right)^{2}\left(9-8 r^{2}\right)\left[4 r^{2}(3 b+5)-16 r^{4}-9 b\right]^{2}}{\left[128 r^{6}+48 r^{4}(3 b-14)-72 r^{2}(3 b-11)+81(b-2)\right]^{2}}, \\
& \pi_{2}^{o *} \\
& =\frac{\left(\alpha-c_{0}\right)^{2}\left(9-8 r^{2}\right)\left[12 r^{2}(7-3 b)-32 r^{4}+27(b-1)\right]^{2}}{\left[128 r^{6}+48 r^{4}(3 b-14)-72 r^{2}(3 b-11)+81(b-2)\right]^{2}} .
\end{aligned}
$$

Definitely, equilibrium $R \& D$ investments, production quantities, and net profits are determined by parameters $\alpha$, $c_{0}, r$, and $b$. With asymmetric product subsidies, firm 1 is not necessary the one with biggest market share. Instead, the market shares of firm 1 and firm 2 mainly depend on $r$ and $b$.

\section{Numerical Simulation and Comparative Analysis}

We obtain specific formulas of equilibrium solutions with symmetric subsidies in Section 2 and asymmetric subsidies in Section 3. Because of the complicated expressions, it is a tough work to make direct comparison of innovation subsidies and product subsidies, not to mention pointing out which one is better. Hence, we conduct numerical simulations to make a comparative analysis of the two subsidies in this section. In the experiment, we set $\alpha=9, c_{0}=4$, and $r=0.5$.

4.1. Comparison of Symmetric Subsidies. Figures 1, 2, 3, and 4 plot the equilibrium solutions for all $b \in(0,2)$. Note that red active lines represent the equilibrium with symmetric innovation subsidies (SIS for short), while dotted lines stand for situations of symmetric product subsidies (SPS for short).

Figure 1 implies that, for $b \in(0.36,0.65)$ and $b \in$ $(1.89,2)$, innovation subsidy is the optimal policy. Notice that innovation subsidy and product subsidy lead to identical social welfares when $b=0.36$ and $b=0.65$, while their effects on firms are different. Otherwise, product subsidy is a better choice for social welfare maximization. If the government intends to stimulate the maximum innovation investments without considering social welfare, product subsidy is much better than innovation subsidy (Figure 2). From the perspective of firms, product subsidy is more attractive and beneficial as long as $b>0.52$. That is, strong preference to consumers' surplus not only brings benefits to consumers, but also creates higher net profits to firms. In addition, as $b \in(0.52,1.89)$, the equilibrium production with symmetric product subsidy is larger than the production with innovation subsidy.

Summing up, the following result emerges from the comparative analysis above.

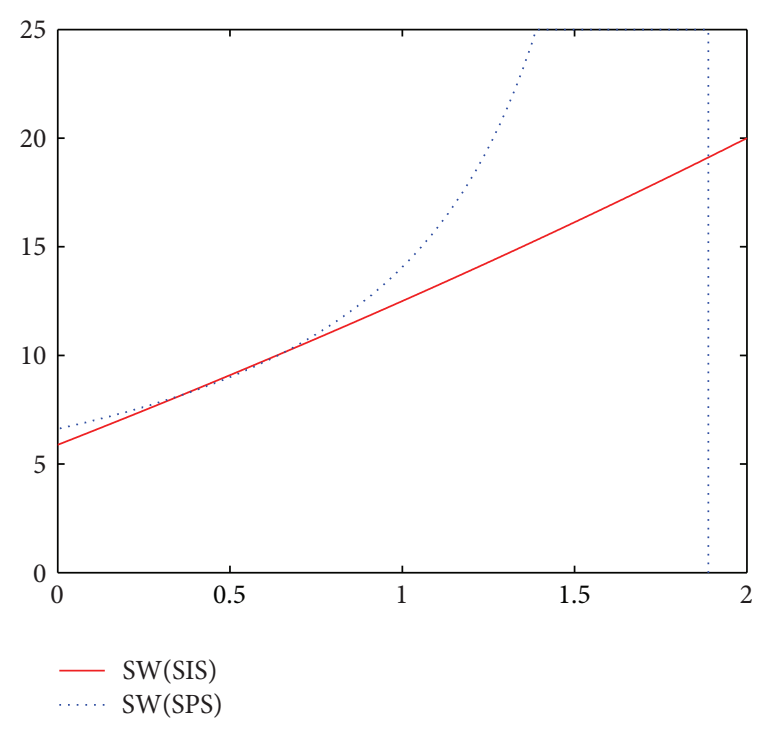

FIgURE 1: Equilibrium social welfares.

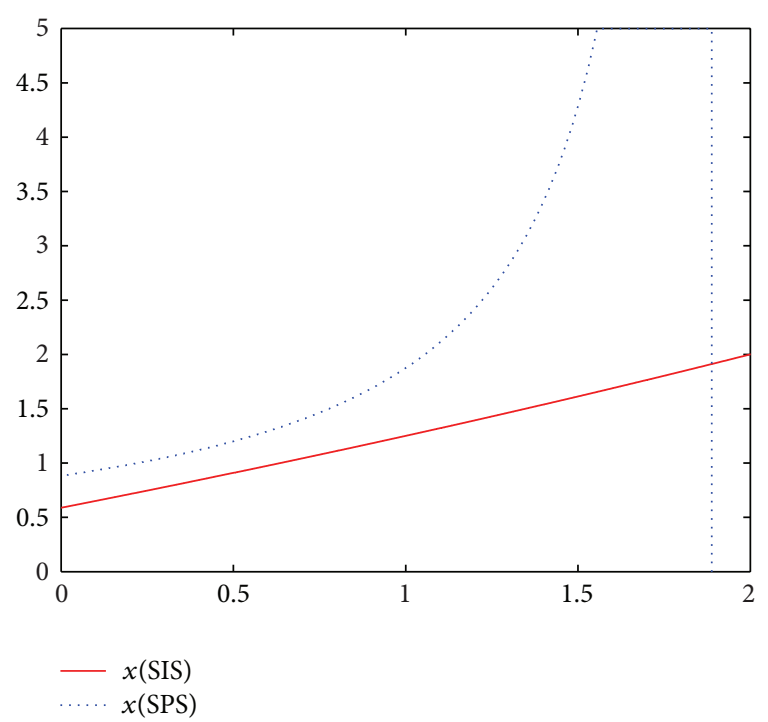

FIgURE 2: Equilibrium R\&D inputs.

Result 1. From the perspective of maximizing social welfare, product subsidy is the optimal policy as long as $b \in$ $(0,0.36)$ and $b \in(0.36,1.89)$. For firms, product subsidy is also a suitable policy to stimulate more R\&D investments, production, and net profits.

4.2. Comparison of Asymmetric Subsidies. From Figures 5, 6,7 , and 8 , we can make visual comparison of asymmetric innovation subsidies and product subsidies. The same as above, red active lines and dotted lines denote the equilibrium solutions of asymmetric innovation subsidy (AIS for short) and asymmetric product subsidy (APS for short), respectively. Notice that we only plot the solutions of the whole market in the figures, without optimums for a single firm. 


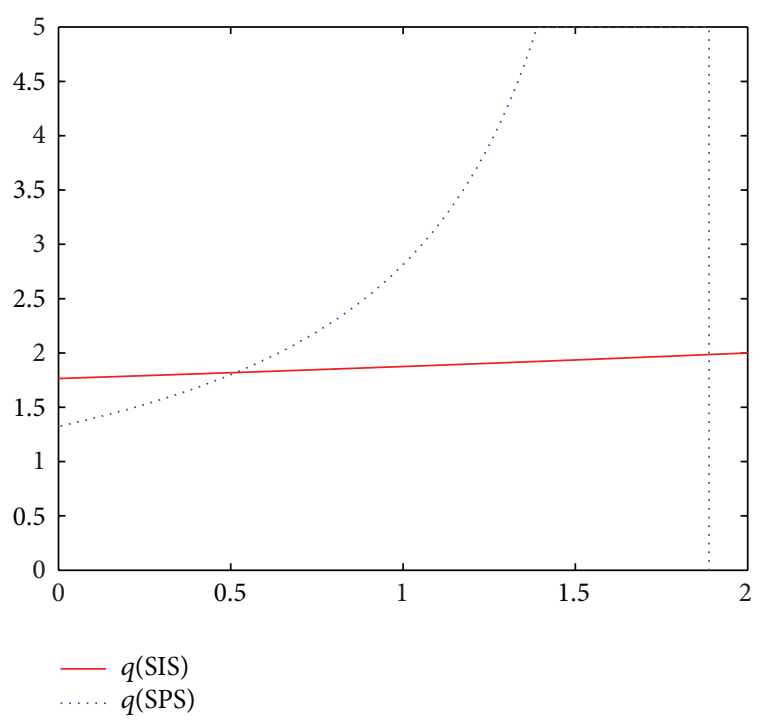

FIgURE 3: Equilibrium production.

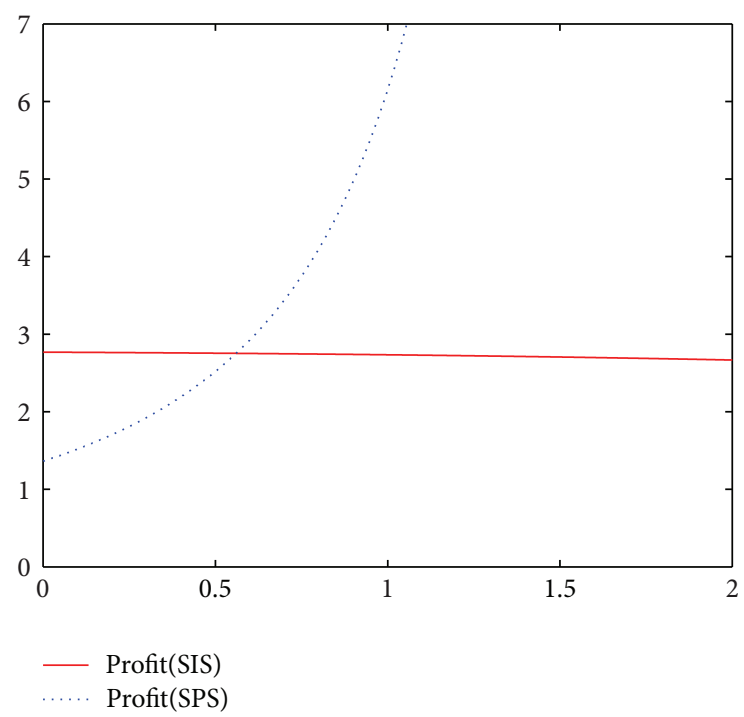

FIgURE 4: Equilibrium net profits.

Even so, the market positions of the two firms' would be analyzed later.

We obtain the following result from the analysis of Figures $5,6,7$, and 8 .

Result 2. Whether the government prefers to enhance consumers' surplus or not, product subsidy is always the optimal policy to maximize social welfare. Product subsidy is also beneficial for firms since it can create higher net profit than innovation subsidy, even though the latter one brings larger $\mathrm{R} \& \mathrm{D}$ investment and production in most cases.

Consider the market positions of firm 1 and firm 2 . In the case of asymmetric innovation subsidy, firm 1 achieves larger market share than firm 2 as $b>1$. If $b=1$, they are symmetric for $q_{1}^{\prime *}-q_{2}^{\prime *}=0$. As $b<1$, firm 2 becomes the one with major

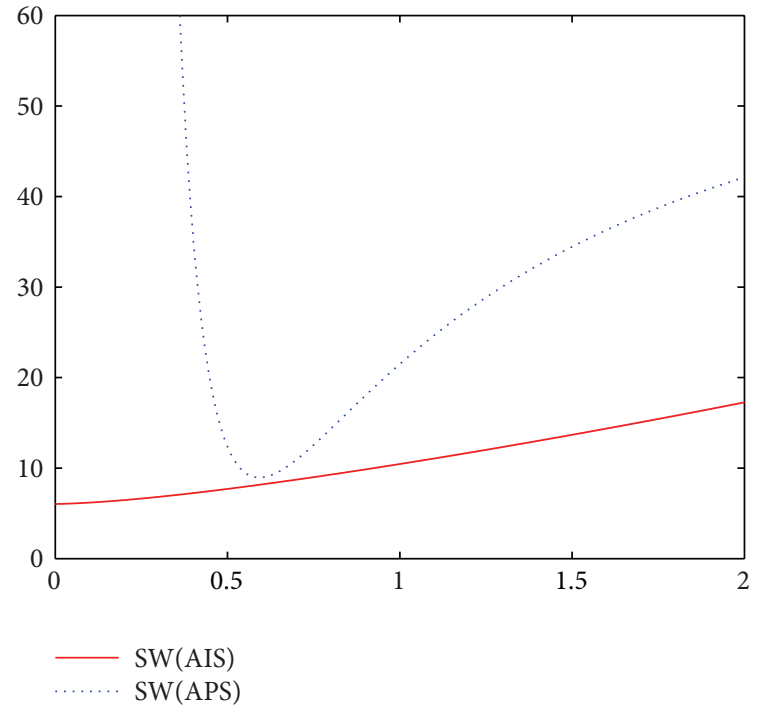

FIgURE 5: Equilibrium social welfares.

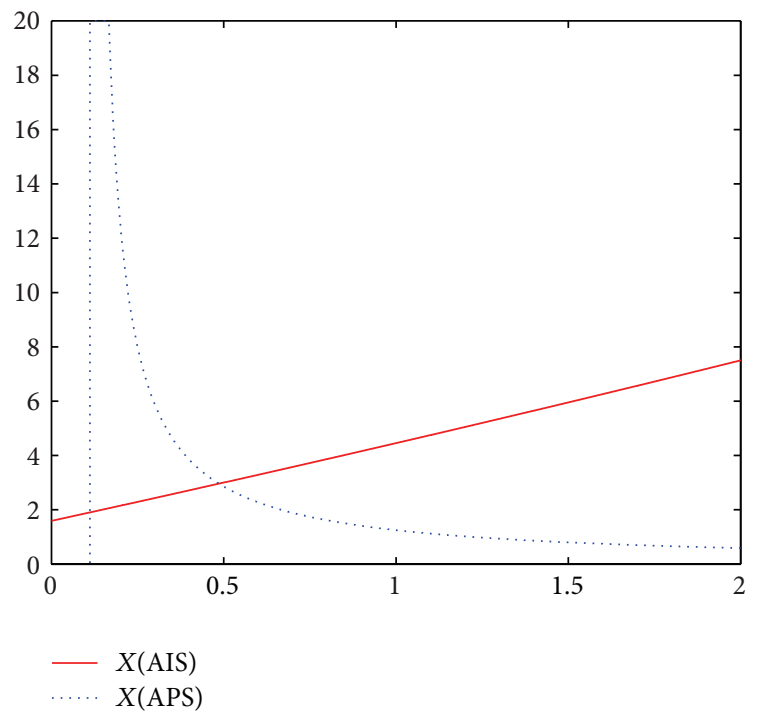

FIgURE 6: Total R\&D inputs.

market share. Thus, stronger preference to consumers' welfare helps firm 1 get advantages in the competition.

In contrast, the situation in the case of asymmetric product subsidy is different. As $b \in(0.11,0.56)$, the production of firm 1 is larger than firm 2 . While $b=0.56$, they are identical in the market. Besides the above, firm 2 produces more since $q_{1}^{o *}-q_{2}^{o *}<0$. In other words, only weak preference to consumers' welfare within specific range can ensure the major market share of firm 1 . Otherwise, firm 2 is more competitive with larger production.

4.3. Comparison of Symmetric Subsidies and Asymmetric Subsidies. Furthermore, we make a simple comparison of symmetric and asymmetric innovation subsidies. Figure 9 implies that symmetric innovation subsidy is better than 


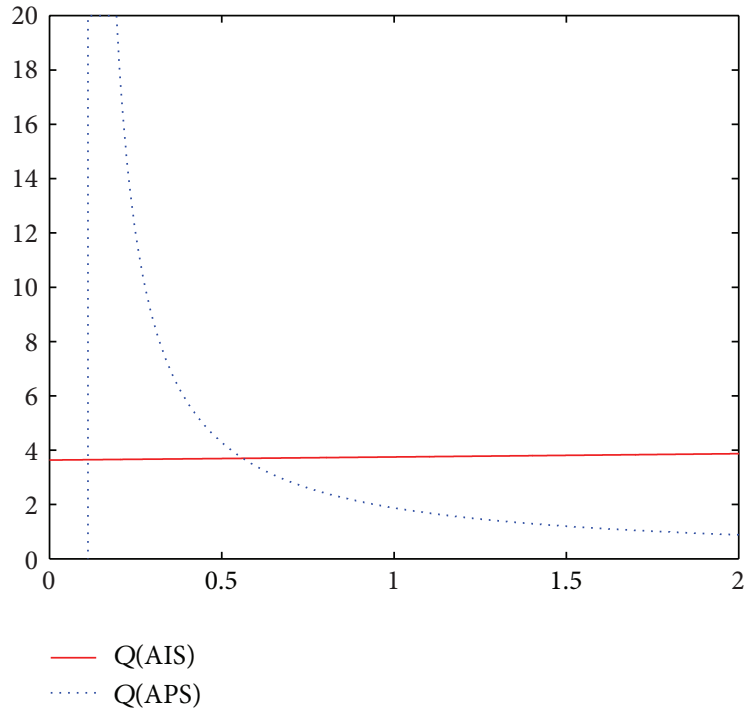

FIgURE 7: Total production.

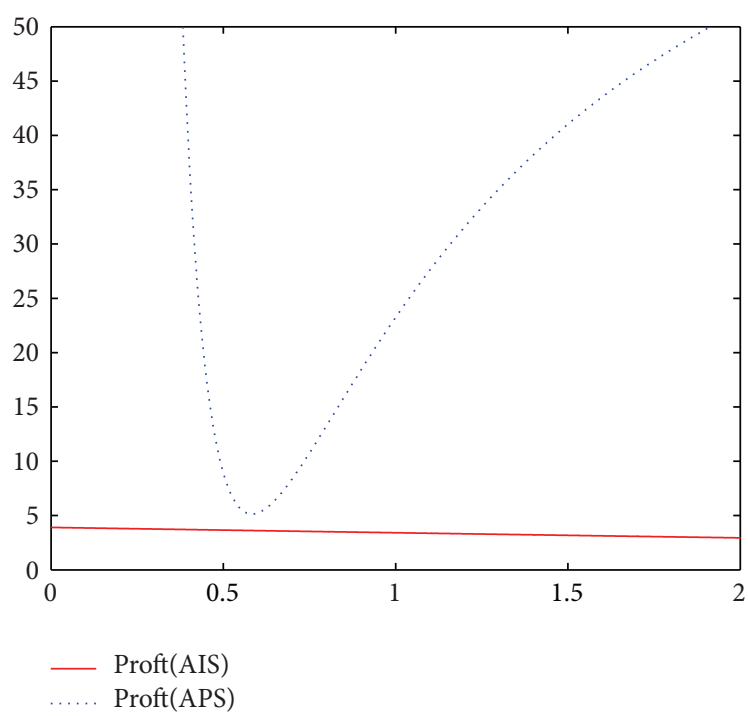

Figure 8: Total net profits.

asymmetric innovation subsidy, since the former one leads to larger social welfare. In contrast, as shown in Figure 10, subsidizing firms asymmetrically increases innovation competition between the two firms, thus leading to more R\&D investments. In addition, no matter whether the government offers innovation subsidy to firms symmetrically or asymmetrically, the total production of the two firms is almost maintained at the same level. follows.

The findings of Figures 9 and 10 can be summarized as

Result 3. If the government determines to provide innovation subsidies, then subsidizing firms symmetrically is a better

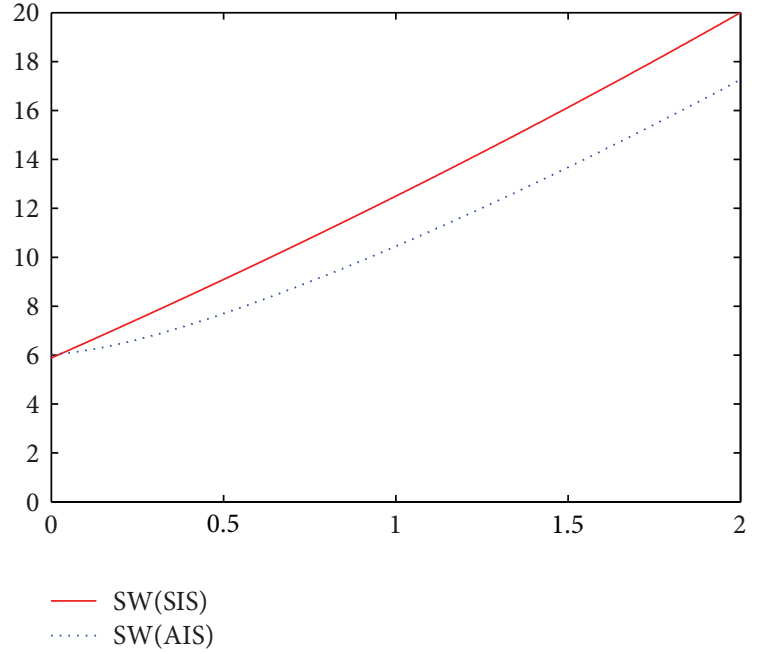

FIGURE 9: Social welfares with innovation subsidies.

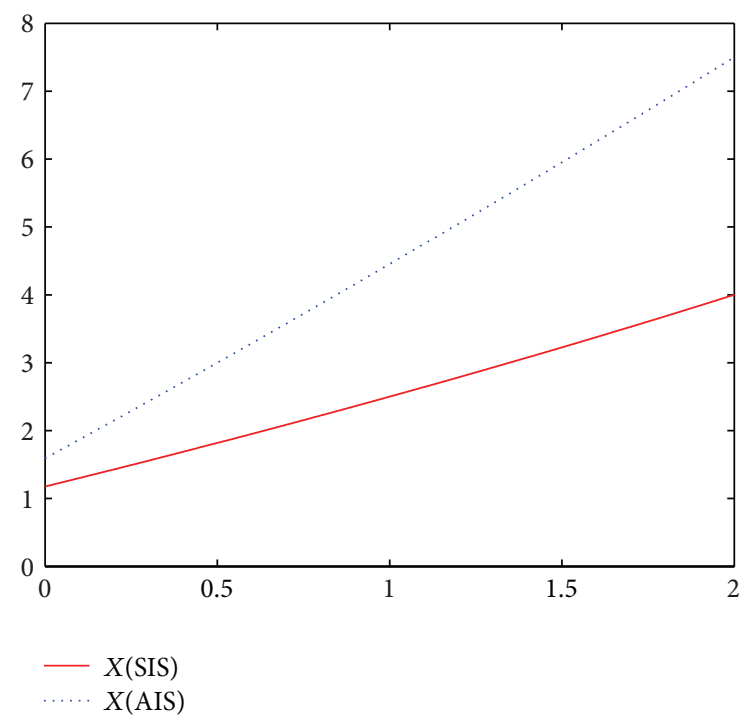

FIGURE 10: Total R\&D inputs with innovation subsidies.

choice for maximization of social welfare. Conversely, asymmetric innovation subsidy becomes the optimal choice from the perspective of stimulating more R\&D investments.

Similarly, Figures 11 and 12 plot equilibrium social welfares and total R\&D inputs with the two forms of product subsidy. Therefore, we can make direct comparison of symmetric product subsidy and asymmetric product subsidy. The result is given below.

Result 4. Offering product subsidy asymmetrically is a correct decision for the government in most cases, since symmetric product subsidy only has advantages within a narrow and specific range.

In detail, as $b \in(0.56,0.68)$ and $b \in(1.53,1.89)$, symmetric product subsidy is better than asymmetric product subsidy. Otherwise, the latter one is better. If the government 


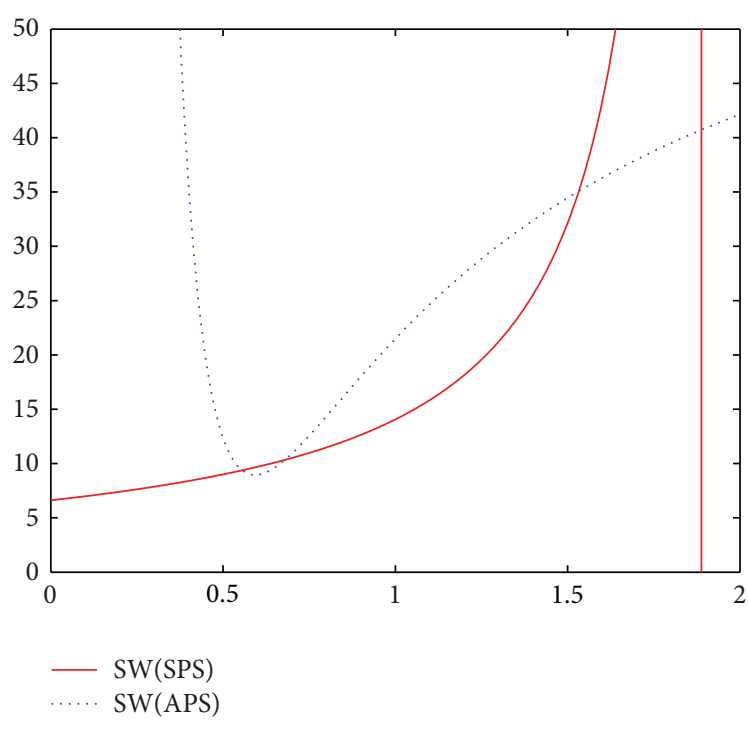

FIGURE 11: Social welfares with product subsidies.

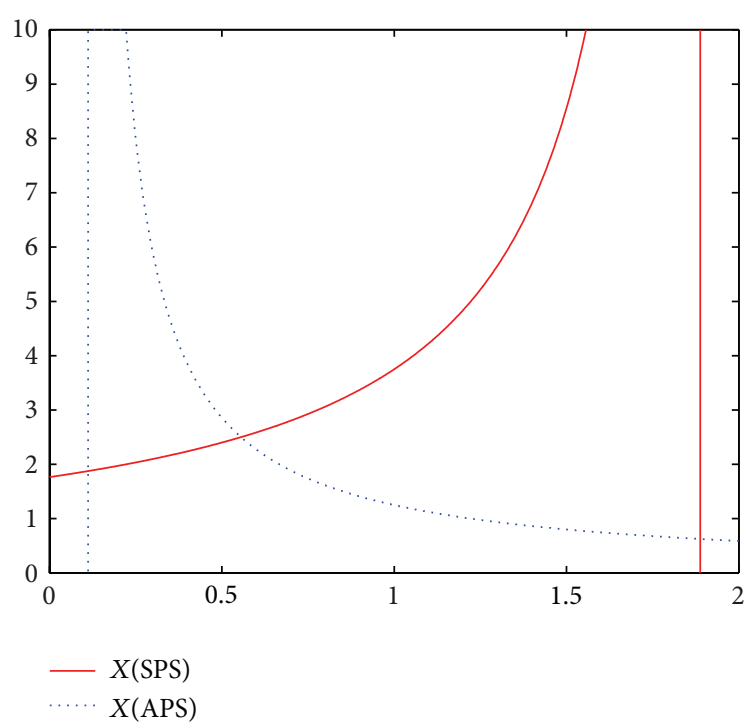

FIGURE 12: Total R\&D inputs with product subsidies.

aims to maximize the total $\mathrm{R} \& \mathrm{D}$ investments of firms, the situation differs. Figure 12 implies that symmetric product subsidy is better for $b \in(0,0.11)$ and $b \in(0.56,1.89)$. The comparison of the two firms' total outputs leads to a similar conclusion.

\section{Conclusion}

Establishing a three-stage game, this paper evaluates the effects of government preference on $\mathrm{R} \& \mathrm{D}$ subsidy policies and makes comparisons between the two major policies, innovation subsidy and product subsidy. We find that stronger preference to consumers' welfare leads to a higher subsidy level, since consumers can enjoy more new products with lower prices. Firms also benefit from the R\&D subsidies as their production costs decrease and production scales increase, thus creating larger net profits.

Results of the numerical simulation present direct comparisons between innovation subsidy and product subsidy. We conduct the comparisons in two situations, symmetric subsidies and asymmetric subsidies. In the case of symmetric subsidies, whether product subsidy or innovation subsidy is the optimal choice depends on the preference of policymakers. Differently, in the case of asymmetric subsidies, product subsidy is always better than innovation subsidy for the goal of social welfare maximization. However, if the government does not set social welfare as a policy objective but intends to promote firms' $\mathrm{R} \& \mathrm{D}$ investments as more as possible, innovation subsidy becomes the best policy option. Such situations often take place in developing countries, which are eager to catch up with developed countries in the field of technology.

Overall, product subsidy is better than innovation subsidy in most cases. Notice that the government expenditure on product subsidy is often more than innovation subsidy, since the equilibrium subsidy rate of the former one is higher than the latter one regularly. Because of the limited budgets, sometimes the government needs to make some adjustments when formulating R\&D subsidy policies. Furthermore, in most instances, compared to asymmetric subsidies, symmetric subsidies are better with more $R \& D$ investments and larger production of the whole market, while asymmetric subsidies lead to a higher social welfare.

\section{Conflict of Interests}

The author declares that there is no conflict of interests regarding the publication of this paper.

\section{Acknowledgments}

Sincere thanks are due to the editor and the reviewers for their helpful suggestions to improve this paper. This work is partially supported by the Guangdong Social Science Foundation (GD13YLJ02).

\section{References}

[1] X. González, J. Jaumandreu, and C. Pazó, "Barriers to innovation and subsidy effectiveness," Rand Journal of Economics, vol. 36, no. 4, pp. 930-950, 2005.

[2] J. Kilponen and T. Santavirta, "When do R\&D subsidies boost innovation: revisiting the inverted U-shape," Bank of Finland Research Discussion Papers, 2007.

[3] Y. H. Chen, P. Y. Nie, and X. H. Wang, "On the relationship between competition and innovation in a duopoly with a single innovator," Economics Bullet, vol. 33, no. 4, pp. 2648-2660, 2013.

[4] P. Y. Nie, "Innovation considering pollution emission with renewable energy input," Energy and Environment, vol. 24, no. 6, pp. 953-964, 2013.

[5] M. Almus and D. Czarnitzki, "The effects of public R\&D subsidies on firms' innovation activities: the case of Eastern Germany," Journal of Business and Economic Statistics, vol. 21, no. 2, pp. 226-236, 2003. 
[6] T. Clausen, "Do subsidies have positive impacts on R\&D and innovation activities at the firm level?" Structural Change and Economic Dynamics, vol. 20, no. 4, pp. 239-253, 2009.

[7] C. Bérubé and P. Mohnen, "Are firms that receive R\&D subsidies more innovative?" Canadian Journal of Economics, vol. 42, no. 1, pp. 206-225, 2009.

[8] A. Catozzella and M. Vivarelli, "Beyond additionality: are innovation subsidies counterproductive?" IZA Discussion Paper 5746, 2011.

[9] B. Montmartin, "Subsidy policy for innovation: a way to reach objectives of both higher growth and equity?" GATE Working Paper 1031, 2010.

[10] Q. Fu, J. F. Lu, and Y. Z. Lu, "Incentivizing R \& D: prize or subsidies?" International Journal of Industrial Organization, vol. 30, no. 1, pp. 67-79, 2012.

[11] A. I. Saracho and J. Usategui, "Innovation diffusion subsidies: supply without precommitment ability and welfare," European Journal of Political Economy, vol. 10, no. 2, pp. 357-372, 1994.

[12] C. D’Aspremont and A. Jacquemin, "Cooperative and noncooperative $\mathrm{R} \& \mathrm{D}$ in duopoly with spillovers," The American Economic Review, vol. 78, pp. 1133-1137, 1988. 


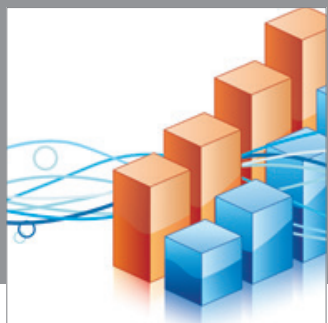

Advances in

Operations Research

mansans

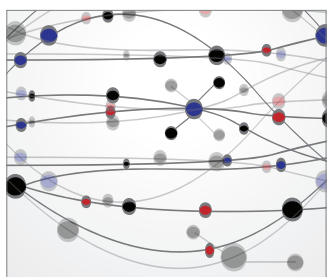

The Scientific World Journal
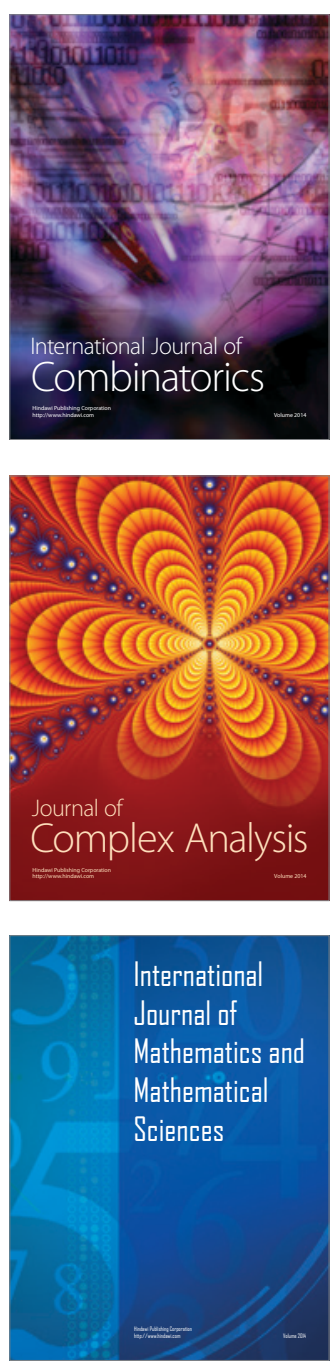
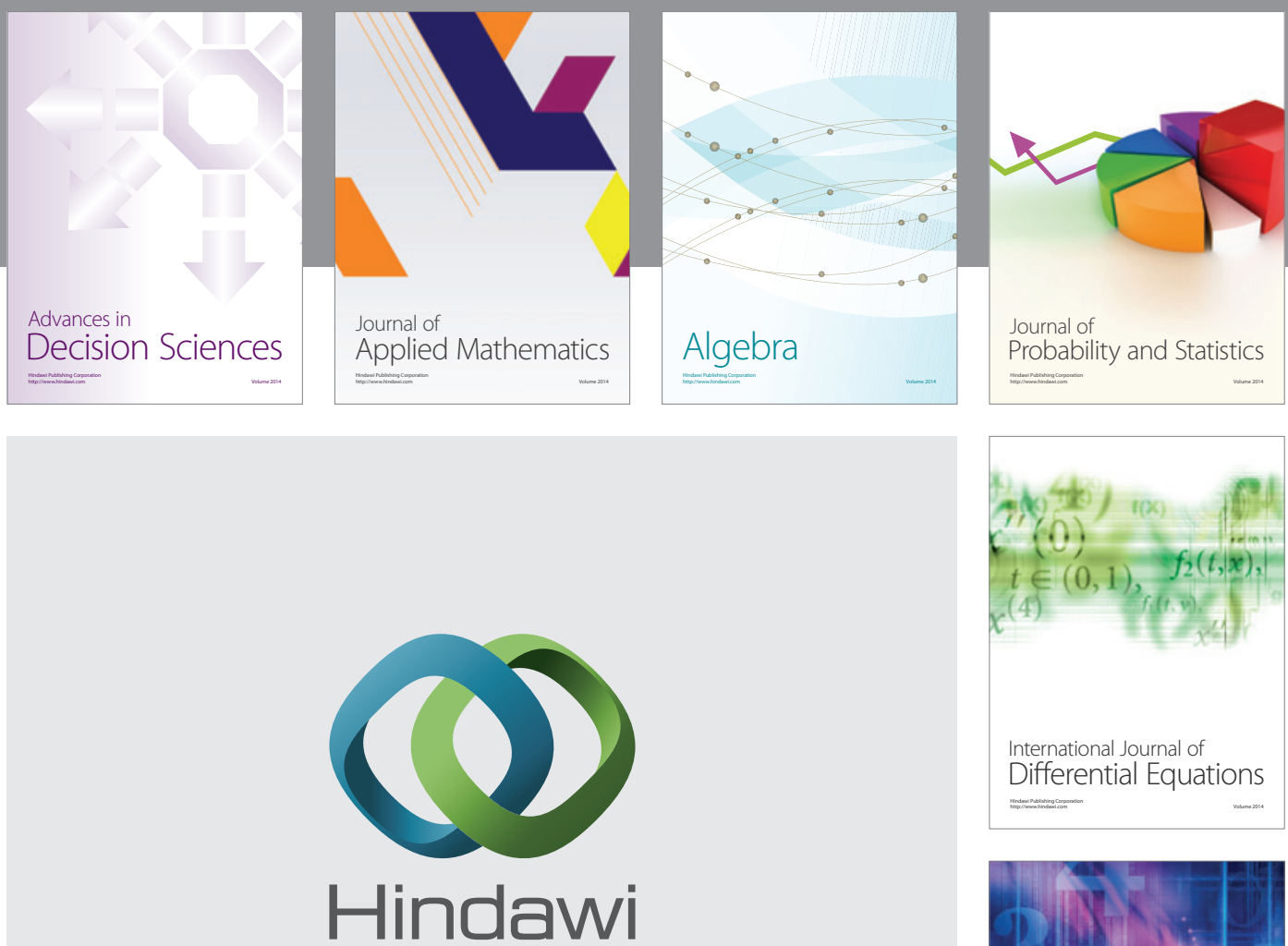

Submit your manuscripts at http://www.hindawi.com
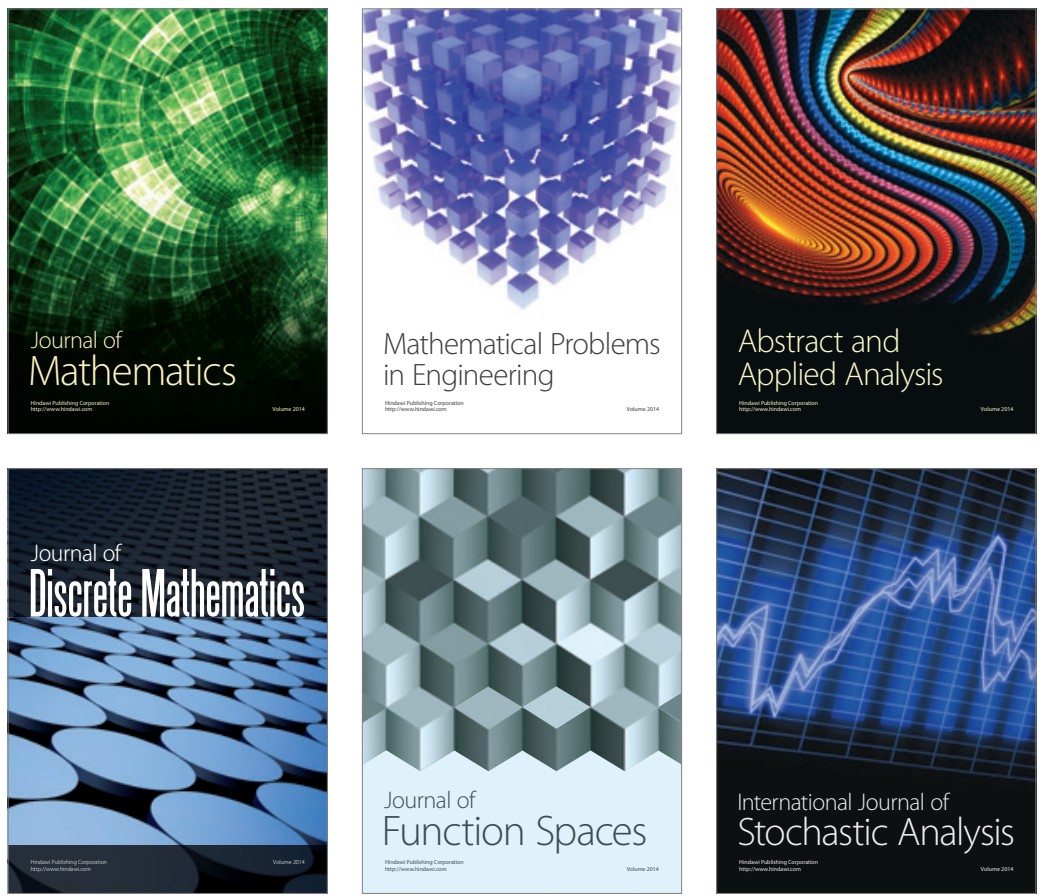

Journal of

Function Spaces

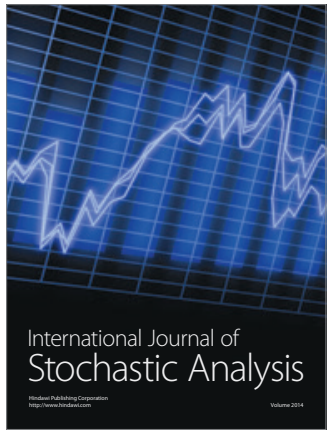

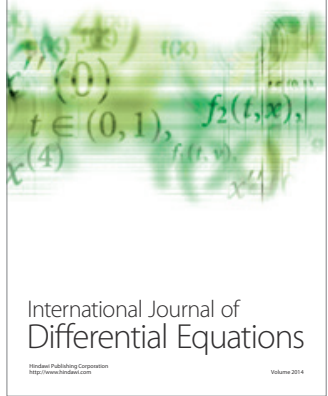
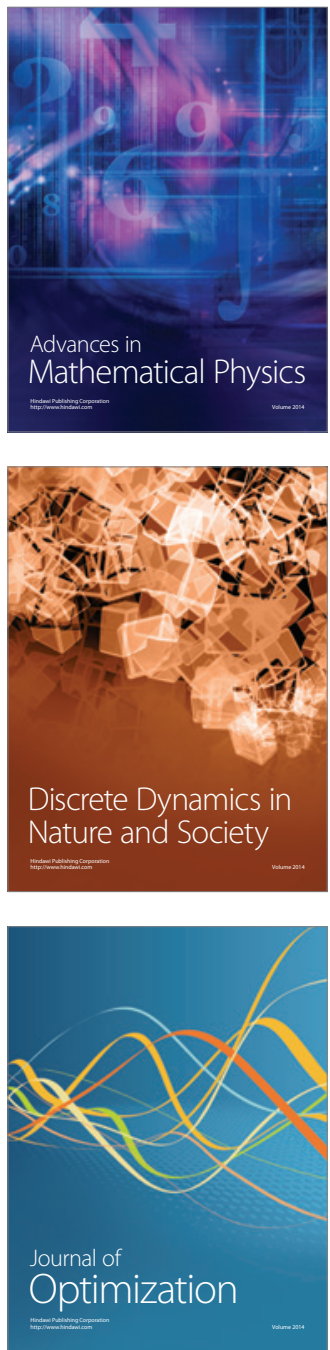